\title{
Procrastination: the poor time management among university students
}

\author{
Naturil-Alfonso, Carmen ${ }^{a^{*}}$; Peñaranda, David S. ${ }^{a}$; Vicente, José S. ${ }^{a}$ and Marco- \\ Jiménez, Francisco ${ }^{a}$ \\ ${ }^{\text {a }}$ Laboratorio de Biotecnología de la Reproducción, Departament of Animal Science, \\ Universitat Politècnica de València, Spain.
}

\begin{abstract}
Academic procrastination is a fact related to the delay or postpone of academic work until last minute. This phenomenon is evident in a vast majority of university students, and its occurrence is increasing. In order to analyse possible causes and/or solutions, we studied if longer time for accomplishing an assignment incentives or avoids procrastination among university students. Results showed that both short and long time-frame groups tended to procrastinate in the same way. Additionally, academic grades did not revealed differences between groups, as the procrastination was the same between groups. Thus, this study shows that even with longer period of time to accomplish a task, university students tend to procrastinate, and thus seem to have a negative effect on their assignment grades. Therefore, it seems a current problem and measures should be developed in order to solve it.
\end{abstract}

Keywords: Time management; Procrastintion; assignments; educational outcomes. 


\section{Introduction}

Procrastination has been considered a dysfunctional behaviour or an irrational delay of behaviour (Ellis \& Knaus, 1977; Silver \& Sabini, 1981) associated with negative outcomes. Academic procrastination was defined as: "to leave academic tasks (preparing for exams and doing homework) to the last minute and to feel discomfort out of this (Slomon \& Rothblum, 1984). Academic procrastination is estimated to occur in $80-95 \%$ of college students (O'Brien, 2002) or at least half of the students (Ozer et al. 2009). Interestingly, this phenomenon seems to be growing (Steel, 2007). Also, procrastination has been negatively correlated with academic performance (Ariely \& Wertrnbrich, 2002; Wong, 2008; Kim \& Seo, 2015). Negative effects have been traditionally related to students' grade point average (GPA), assignment grades, quiz scores and course grades (Steel et al. 2001; Kim \& Seo, 2015).

In academic context, procrastination trait includes achivement motivation or hope for success, planning and time manage skills, work discipline, study motivation, and selfcontrol and cognitive study-skills (Schouwenbrug, 1995). Therefore, it has particularly important consequences for university students, such as waste of time, poor performance, increased stress, anxiety and depression (Chu \& Choi, 2005, Essau et al. 2008). These factors led to an increase in pressure due a time reduction which reduces accuracy and consequenlty a reduction in academic performance (Van Eerde, 2003).

Previous studies have suggested that the relationship between procrastination and academic performance is influenced by the ability of the students. Previously, Ferrari (1991) showed that students with greater ability tend to procrastinate more tan those with lower ability. However, it has been recently published that these students with high cognitive abilities may obtain worse educational outcomes or fail to accomplish the educational program if they procrastinate (De Paola \& Scoppa, 2015).

The study was conducted with the objective of analyzing the time management in deferring academic activities among university students.

\section{Methods}

\subsection{Context}

The present study was delimited to the School of Agricultural Engineering and Environment of The Universidad Politécnica de Valencia, Spain. The population of the study consisted on undergraduated students. The samples of the study involved 106 students divided in two different classroom groups named A and B. 


\subsection{Procrastination trial: indices of academic performance}

The day of the subject presentation (26/01/15), both groups of students were told about the assignment which would count as a $5 \%$ of the final grade of the subject. The assignment was a bibliographic report in the topic of animal models in biological and biomedical research. Table 1 shows the guidelines of the assignment provided for both groups of students.

Table 1. Guidelines for the Animal Model assignment

\begin{tabular}{l|l}
\hline Assignment: Animal Model & $\begin{array}{l}\text { Bibliographic report about the appliance of an animal } \\
\text { specie as animal model }\end{array}$ \\
\hline Type & Work in pairs \\
\hline Structure & Title \& authors \\
& Abstract \& keywords \\
& Body text (including figures and tables) \\
& Conclusions \\
& References \\
\hline Format & A4 size \\
& Paper length: 5 pages \\
& Font: arial, 11, 1.5 spacing \\
\hline
\end{tabular}

In order to evaluated the time management between students of both groups, different deadlines were established. In group A deadline was the 15/03/2015 (1 month and a half after the communication), while group B deadline was 31/05/2015 (almost 3 months later)(figure 1). The number of weeks a student takes to accomplish the enrollment procedure after notification was considered as a proxy of individual procrastination. The theoretical estimation of an average student to accomplish the task was within 10 hours.

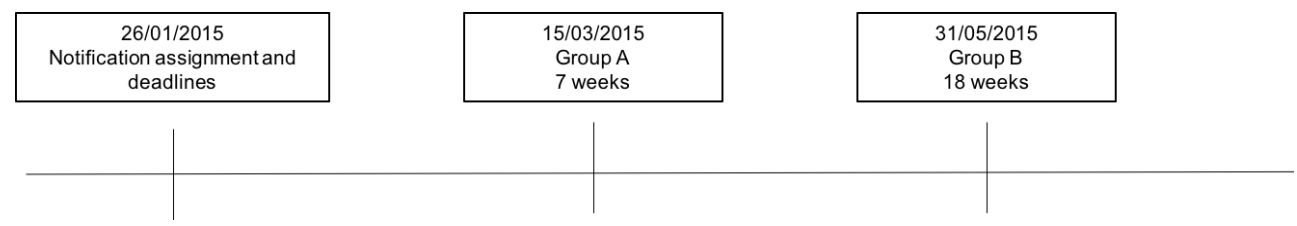

Figure 1. Timeline of the assignment

Additionally, the students' assignment grades was analysed in order to analyse the effect of procrastination in academic outcomes. A scoring guide was used to evaluate the quality of students' assignments (table 2). This rubric was communicated to the students the first day of lessons. 
Table 2. Animal Model Assignment Rubric

\begin{tabular}{l|l}
\hline Content & $\mathbf{7 0}$ \\
Model originality (mouse=5, horse=20) & 20 \\
Physiological description of the specie & 20 \\
Model appliance & 20 \\
Scientific quality and depth & 10 \\
\hline Formal aspect & $\mathbf{3 0}$ \\
Compliance with the guideline (deadline, length, etc.) & 10 \\
Figures and tables & 10 \\
Reference & 10 \\
\hline
\end{tabular}

Finally, the numer of consultations about the task of each group were recorded.

\subsection{Data analysis}

We recorded the week on which students accomplished their assignment and we built a measure of procrastination by considering how close this date was to the deadline. To be more precise, the main variable procrastinatin took values from 1 to 5 depending on the week the students submitted with their assignment (Table 3).

Table 3. Procrastination variable distribution

\begin{tabular}{c|cc}
\hline Group & Week of accomplishment & Procrastination variable \\
\hline \multirow{3}{*}{ A } & 3 & 1 \\
& 4 & 2 \\
& $5-6$ & 3 \\
& 7 & 4 \\
& Out of time & 5 \\
\hline \multirow{3}{*}{ B } & $1-5$ & 1 \\
& $6-10$ & 3 \\
& $11-16$ & 4 \\
& $17-18$ & 5 \\
\hline
\end{tabular}

To measure the level of procrastination among these students, a descriptive analysis by a chi-square test was performed. To compare assignment grades among groups a General Linear Model was performed. The consultations during the assigment duration were analysed using a probit link function. Differences of $\mathrm{p}<0.05$ were considered significant. All analysis were performed with a SPSS 21.0 software package (SPSS In., Chicago, IL, USA, 2002). 


\section{Results}

Firstly, the number of consultations revealed no differences between groups ( $0.17 \pm 0.07$ and $0.29 \pm 0.093$ consultations for the A and B groups, respectively). As indicate in table 4, students on average accomplished their assigment on the last period. The mean procrastination variable for both groups was $4(4.0 \pm 0.09$ and $3.9 \pm 0.09$, for the A and B groups, respectively), with the $78.8 \%$ of students submitting the assigments on the last week. None of teams among different groups were non-procrastinators, as there were no assigments submitted in the procrastination variable 1 and 2 . Slight procrastinators would be those submitting in procrastination variable 3 , with only $11.5 \%$ of students. Additionally, it should be highlighted that no team of B group students submitted the assigments after the deadline, while almost $10 \%$ of the students from the A group submitted their work late.

The mean grade in assigments neither reported differences between groups. The A group reported an average grade of $6.4 \pm 0.29$, while the B group average grade was $6.2 \pm 0.31$.

Table 4. Descriptive analysis

\begin{tabular}{cccccc} 
& \multicolumn{5}{c}{ Procrastination variable (\%) } \\
Groups & 1 & 2 & 3 & 4 & 5 \\
\hline A & 0 & 0 & $7.7(4)$ & $38.5(20)$ & $9.6(5)$ \\
B & 0 & 0 & $3.8(2)$ & $40.4(21)$ & 0 \\
Total & 0 & 0 & $11.5(6)$ & $78.8(41)$ & $9.6(5)$ \\
\hline \multicolumn{5}{c}{ (n): number of assignments for each \% }
\end{tabular}

\section{Discussion}

In education, the term academic procrastination is commonly used to denote a postpone in students' academic work. It has been widely reported that academic procrastination produces negative effects on students' performance (Ariely \& Wertenbroch, 2002; Wong, 2008; De Paola \& Scoppa, 2015; Kim \& Seo, 2015). In fact, high levels of procrastination make students unable to regulate and organize them achieve their academic goals (Essau et al. 2008). Different factors appear to contribute towards procrastination among university students as lack of commintment, lack of encouragement or inappropriate time management skills (Hussain \& Sultan, 2010).

The overall results of our study showed no differences neither in procrastination nor in assignments' mean grade between both groups. Although it has been previously reported that longer times for completing a task promote procrastination (Goode, 2008), we 
observed similar tendency to procrastinate between both groups of students. Thus, the tendency to procrastinate between B group students could be explained by the longer time to accomplish with their assignment (18 vs 7 weeks for the B and A groups, respectively). Nevertheless, it is interesting to highlight that none of the B group students submitted the assignment out of time, while almost $10 \%$ of the A group students did. Another point to consider is if B students deliberately decide to procrastinate (Kim et al. 2017). Nonetheless, this may not be the case, as the deadline for B groups students coincided with the final term exams. In fact, this could explain two of the studied factors: on the one hand, B students tend to procrastinate as much as A students in spite of the length of the deadline and the proximity of final exams; on the other hand, procrastination may be the consequence of the low assignment grade of groups, and determines the harmful effect of delaying on academic achivements.

Tuckman (2002) proposed a long time for accomplishing a task as a measure to battle procrastination. That work suggested that tasks far away in time may reduce procrastination. However, our study shows that even longer time for accomplishing (almost 4 months) and the proximity of the final exams did not persuade students to procrastinate. Therefore, as independently of the time task all students seem to procrastinate, measures against procrastination between university students should be carried out by the academic institutions. Previous studies have proposed some remedial measures such as guidance and counselling services (Hussain \& Sultan, 2010).

In addition, we studied if procrastination was correlated with educational performance. We determined that no differences exist on assignment average mark between groups, being the same mean grade for A and for B groups. Although De Paola \& Scoppa (2015) described that students who procrastinate may obtain a low academic outcome, the lack of differences observed in our study could be explained based on the similar mean procrastination variable observed for both groups.

In conclusion, this study shows that even with longer deadline times and the proximity of the deadline to their final term exams university students tend to procrastinate.

\section{Acknowledgements}

This project has received funding from the Vicerectorado de Estudios, Calidad $y$ Acreditación of the Universitat Politècnica de València (UPV) under Proyectos de Innovación y Mejora Educativa programme (PIME/2017/B/010) and the School of Agricultural Engineering and Environment (ETSIAMN) of the Universitat Politècnica de València (UPV). 


\section{References}

Ariely, D., \& Wertenbroch. (2002). Procrastinations, deadlines, ans performance: self.control by precommitment. Psychol., 13(3), 219-224.

Chu, A.H., \& Choi, J.N. (2005). Why not procrastinate? Development and validation of a new active procrastination scale. The Journal of Social Phychology, 149, 195-211.

De Paola, M., \& Scoppa, V. (2015). Procrastination, academis succes and the effectiveness of a remedial program. Journak of Economic Behaviour \& Organization, 115, 217-236.

Ellis, A., \& Knaus, W.J. (1977). Overcoming procrastination. New York: Institutw of Rational Living.

Essau, C.A., Ederer, E.M., O’Callaghab, J., Aschemann, B. (2008). Doing it now or later? Correlates, predictors and preventions of academic, decisional and general procrastination among students in Austria. Presentation at $8^{\text {th }}$ Alps-Adria Psychology Conference, October 2-4, Ljubljana, Slovenia.

Ferrari, J.R. (1991). Self-handicapping by procrastinators: Protecting slef-steem, social.steem, or both? Journal of Research in Personality, 25, 245-261.

Goode, C. (2008). Effects of academic procrastination: Students procrastination affects more than grades. http://homeworktree.com/media/news-releases/academicprocrastination.

Hussain, I., \& Sultan, S. (2010). Analysis of procrastination among university students. Procedia Social and Behavioural Sciences, 5, 1897-1904.

Kim, K.R., \& Seo, E.H. (2015). The relationship between procrastination and academic performance: A meta-analysis. Personality and Individual Differences, 82, 26-33.

Kim, S., Fernandez, S., Terrier, L. (2017). Procrastination, personality traits, and academic performance: When active and passive procrastination tell a different story. Personality and Individual differences, 108, 154-157.

O'Brien, W.K. (2002). Appliying the trans-theoretical model to academic procrastination. Dissertation Abstracts Internations: Section B: The Sciences and Engineering, 62(11B), 5359.

Ozer, B.U., Demir, A., \& Ferrari, J.R. (2009). Exploring academic procrastination among Turkish students: Possible gender differences in prevalence and reasons. Journal of Social Psychology, 149, 241-257.

Schouwenburg, H.C. (1995). Academic procrastination: Theoretical notions, measurements, and research. In J.R. Ferrari, J.L. Johnson, \& W.G. McCown (Eds.). Procrastination and task avoidance: Tehory, research, and treatment (pp. 71-96). New York, NY: Plenum Press. 
Silver, M. \& Sabini, J. (1981). Procrastinating. Journal of the Theory of Social Behaviour, 11, 207-221.

Solomon, L.J., \& Rothblum, E.D. (1984). Academic procrastination: frequency and cognitive-behavioral correlates. J. Couns. Psychol., 31(4), 503-509.

Steel, P. (2007). The nature of procrastination: A meta-analytic and theoretical review of quitessential self-regulatory failure. Phychological Bulletin, 133(1), 65-94.

Steel, P., Brothen, T., Wambach, C. (2001). Procrastination and personality, performance, and mood. Personality and Individual Differences, 30(1), 95-106.

Tuckman, B. (2002). The relationship of academic procrastination, rationalizations and performance in a web course with deadlines. Annual Meeting of the American Psychological Association: Chicago.

Van Eerde, W. (2003). A meta-analytic derived nomological network of procrastination. Personality and Individual Differences, 35, 1401-1418.

Wong, W.K. (2008). How much time-inconsistency is there and does it matter? Evidence of self-awareness, size and effects. Journal of Economical Behaviour and Organization, 68(3), 645-656. 